\title{
APRENDIZAJE INVISIBLE. HACIA UNA NUEVA ECOLOGÍA DE LA EDUCACIÓN
}

\section{INVISIBLE LEARNING. TOWARDS A NEW EDUCATION ECOLOGY}

\author{
Cristóbal Cobo Romani y John W. Moravec ${ }^{2}$ \\ Ediciones de la Universidad de Barcelona, \\ España, 2011, 239 p.
}

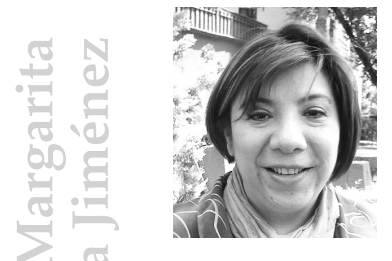

Doctora en Pedagogía, UPAEP. Maestra en Enseñanza Superior, Universidad La Salle, México. Licenciada en la Atención de Personas con Trastornos de Audición y Lenguaje, Instituto Superior de Docentes en Educación Especial, México. Profesora en Educación Primaria, Normal «La Florida», México. Se ha desempeñado en la docencia en todos los niveles educativos; ha formado parte de consejos consultivos como asesora educativa en el DF y en diferentes Estados de la República. Desde 1991 es docente en diversas universidades en nivel superior. Profesora invitada en clases de posgrado en universidades del DF e interior de la República. Perteneciente al Comité de Reactivos del EGEL Pedagogía y Ciencias de la Educación de Ceneval.

Correo electrónico: [mejimene@up.edu.mx].

1 Doctor en Ciencias de la Comunicación, Universidad de Barcelona. Académico e investigador asociado, Instituto Internet de Oxford. Profesor e investigador en FLACSO-México, de 2005 a 2010.

2 Docente de la Escuela de Educación y Desarrollo Humano y del Posgrado de Estudios sobre Innovación, Universidad de Minnesota. Editor de Educacion Futures. 
Reflexionar en el avance de las Tecnologías de la Información, y específicamente de Internet, es recapitular en el conocimiento social entre instituciones, pero sobre todo en su influencia en las personas; desde su surgimiento, a finales de los 60, al lanzamiento de la www en los 90, ha impactado no solo en el mundo científico, social y cotidiano, sino también en las instituciones educativas, en las aulas, en la enseñanza y en las personas que aprenden.

El desarrollo de la tecnología y del Internet ha mostrado adelantos significativos pero, en el campo del proceso enseñanza-aprendizaje, no se perciben en los aprendizajes formales estudiados en las instituciones educativas. Por ello algunas preguntas eje, planteadas en el texto, se centran en por qué estos avances no impactan en las evaluaciones o por qué no se denota el rendimiento a partir de esta evolución.

La cercanía e interacción del estudiante con su contexto, pero principalmente con el mundo de Internet, propicia experiencias, contenidos, ideas, relación con lugares y personas. Esto gesta un aprendizaje que Nonaka y Tekeuchi denominan subjetivo e intuitivo, y que es personal. Este aprendizaje no se toma en cuenta en la educación formal y pasa desapercibido en el contexto del aula.

El saber originado por la interacción tecnológica promueve un aprendizaje tácito (concebido por Polanyi) y práctico que orienta la acción de quien lo vive; es desconocido por los otros, que no valoran su utilidad; y quien lo posee tampoco pondera su relevancia. Cuánto podría aprovecharse de ese conocer en el contexto educativo formal, pues implicaría manejar información, y desarrollar habilidades y procesos.

Este entorno del estudiante posibilita lo que se considera como un aprendizaje invisible que, en el presente libro, se plantea como una nueva perspectiva de ver y proponer preguntas que influyen -o pueden influir- en la educación. Este es un aprendizaje que posee la persona y que no se ve, que no se observa, que está conformado con lo continuo, lo informal y se gesta a partir de las interacciones cotidianas.

Es un aprendizaje que involucra la mejora en diferentes contextos y escenarios, y que comprende el desarrollo de procesos mentales, actitudes y perspectivas de concebir el mundo. 
Aprendizaje invisible es una llamada a construir de manera conjunta un paradigma de educación que resulte inclusivo, que no se anteponga a ningún planteamiento teórico en particular pero que ilumine áreas del conocimiento hasta ahora desatendidas. Aprendizaje invisible no pretende proponer una teoría como tal, sino una metateoría capaz de integrar diferentes ideas y perspectivas. Es por ello por lo que hemos querido denominar protoparadigma, que se encuentra en fase beta y en plena etapa de construcción (p. 22).

En 2007, Cobo y Moravec emplearon por vez primera el término «aprendizaje invisible» al reflexionar acerca de las implicaciones de los dispositivos móviles en el aprendizaje y su relación con posturas de enseñanza basadas en una colectivización del saber, involucrando la relación de la persona con las instancias que generan el aprendizaje colaborativo, el descubrimiento y las experiencias en diversos contextos, mismos que promoverán la construcción del conocimiento a partir del aprendizaje informal.

Diversas posturas educativas centraron sus estudios en el aprendizaje a partir del entorno, y de la interacción y adaptación con este, así como la relevancia en la continuidad del aprender pero, a pesar de reconocer su importancia, la educación formal no ofrece flexibilidad y apertura ante este aprendizaje: no se toma en cuenta.

Adaptar el proceso de enseñanza aprendizaje al contexto actual, enriquecerá la manera de aprender; no tanto de qué aprender, sino «cómo aprender» y para qué hacerlo. Se aprovecharían, así, las habilidades y destrezas que son esenciales en lo cotidiano, en lo social.

De aquí la importancia de promover un aprendizaje adaptable que responda de manera efectiva a la realidad y a sus problemas, que involucre ese aprender en la vida y no solo en un contexto teórico. Este aprendizaje — que por ser adaptable y relacional, promueve en la persona el ser multitask - posibilita también el comunicarse con los demás en su mismo entorno y en otros diversos. Hoy, los estudiantes involucrados en escenarios de la web, se contactan y participan con personas de diversos países e idiomas. Estas habilidades relevantes 
en el aprendizaje, no se toman en cuenta en la educación formal, pero sí en la vida cotidiana.

El fundamento social del aprendizaje invisible se sustenta en los denominados espacios de flujo estudiados por Manuel Castells, pues se considera que todas las actividades que realiza la persona, se organizan en un espacio de flujos y conexiones que posibilitan el desarrollo de conocimientos, y la mejora en sus procesos y actitudes. Estos espacios de flujo que inciden en el aprender requieren considerar los ejes del aprendizaje invisible (p. 33-41):

1. Las competencias no evidentes resultan invisibles en entornos formales.

2. Las TIC se hacen invisibles.

3. Las competencias adquiridas en entornos informales son invisibles.

4. Las competencias digitales resultan invisibles.

5. Existen ciertas prácticas empleadas en la escuela/universidad que es necesario invisibilizar.

Lo habitual, lo que se vive en el día a día y que permea procesos y actitudes - relevantes en el aprender - no son visibles, no se potencializan en el aprendizaje formal. El planteamiento de Cobo y Moravec alude a la importancia de interrelacionar las habilidades cotidianas y generar espacios de flujo en la educación formal, en la enseñanza.

La relación en diferentes escenarios sociales permeados con la web, permite la interrelación de personas («nómadas del conocimiento») que trabajan en el conocimiento y en la innovación conformando - a partir de características fundadas en la imaginación, creatividad y colaboración- espacios sociales comunes. Ellos son los knowmads ${ }^{3}$,

3 Juego intraducible ya que, en inglés, los «nómadas» son los «nomads» y aquí se juega, justamente, con la similar pronunciación. N. del e. 
término creado por Moravec, valorados por su conocimiento personal (p. 56). El planteamiento hacia la educación formal se centra en lo poco que esta ha hecho para evolucionar a una sociedad 3.0 y para formar a la persona a ser un knowmad, dejando de lado lo que Freire denominó «educación bancaria».

Paradójicamente, y a pesar de que la educación es un elemento clave tanto para el desarrollo del capital humano como para los futuros del desarrollo humano, esta ha sido concebida para cambiar muy lentamente. [...] Las escuelas tienen que formar estudiantes capaces de diseñar futuros empleos, industrias y campos de conocimiento. Es decir, han de servir como plataformas en las que se pueda reflexionar sobre el futuro, no como lugares de rezago (p. 63).

El aprendizaje invisible se apoya en la tecnología, la cual debe de considerar: propósito definido, desarrollar el mindware al potenciar la imaginación, la creatividad, la innovación y el hacer, por ello debe de ser concebido como una herramienta social y experimental del aprendizaje, el cual evoluciona constantemente; este conocer no puede detenerse en situaciones estáticas formales; requiere apoyarse en la tecnología para desarrollar habilidades humanísticas que posibiliten a la persona adaptarse a una época de constante cambio e incertidumbre.

La sola tecnología no generará el milagro educativo. Existen diversas condiciones complementarias y factores que permiten incidir en la educación de la persona, tales como: el profesor, el aprovechamiento de los aprendizajes invisibles del estudiante, la capacidad de interrelación entre docente, estudiante, entorno y contenido; la relación con los otros; el desarrollo de las habilidades, procesos y actitudes. En suma, es indispensable aprovechar, en el aula, que el estudiante es un ser en continuo aprendizaje.

La innovación tecnológica llegó antes que otras (social, institucional, pedagógica...), por ello es que la escuela del siglo XXI cambió, pero solo en la forma: con diversos espacios en las aulas dedicados al uso de la tecnología. Esto supone un espejismo tecnológico, pues estos progresos no se reflejan en mejores resultados en el contexto educativo. 
Para el avance educativo es crucial mirar la inclusión tecnológica desde otra perspectiva y acompañarla de capacitación docente: formar a un profesor $e$-alfabetizado, conocedor de los avances tecnológicos que le permitan, por ende, generar estrategias que potencien el aprendizaje fuera del aula, empleando las nuevas tecnologías en la educación formal y que implican:

[...] las oportunidades de aprendizaje (y des-aprendizaje) que florecen cuando los sujetos que cuentan con un conjunto básico de competencias informáticas adoptan creativamente las TIC para resolver, explorar, colaborar, experimentar. Es decir, autoaprendizaje (p. 92).

El aprendizaje invisible se sustenta también en la postura de Dewey, con su idea pedagógica de experiencia, conformada por la continuidad, debido a que el aprendizaje no es aislado, y gracias a la interacción, el entorno influye en el aprendizaje; de aquí la importancia de trabajar en colaboración, construyendo socialmente el conocimiento.

Tal como indica Cobo, lo esencial no es lo que está en la Red; lo enriquecedor es la interacción del docente y los estudiantes a partir de lo que existe en la Red. La Red no sirve solo para conectarse, sino para desarrollar procesos en el estudiante que lo llevarán a hacer un uso más inteligente, estratégico y social de esta; lo valioso no es acceder a la información, sino la creación social, la capacidad de atención que esta generará.

La tecnología no es trascendente si no es considerada como una herramienta para conformar el aprendizaje social y la inteligencia colectiva, pues el conocer implica generar. La educación formal supone incidir en la colectividad del aprendizaje.

En general se visualiza una domesticación en la relación con la tecnología: una apropiación mediante la aceptación, resistencia y negociación, pero existe una «invisibilización» de su valor: no en lo que se aprende, sino cómo, dónde y cuándo se aprende. Es necesario transformar el sistema rígido de la educación (p. 122-131), acercando al docente al aprendizaje ubicuo, incidental, planteando una comunidad de aprendizaje colectiva e inclusiva en donde se construyan de manera 
individual, pero también social, contenidos en repositorios de valor (no solo en la Red, sino en estructuras semánticas). Es ineludible para el docente pensar en nuevos modelos de enseñanza aprendizaje que no se sustenten solo en la transferencia de datos - con una estructura estática-, sino que se piense en nuevos esquemas de evaluación que desarrollen capacidades de filtrar o seleccionar información y de crearla, aprovechando el aprendizaje invisible (social y cotidiano) de sus estudiantes.

Reinventar el aprendizaje es un compromiso educativo: el estudiante debe ser capaz de valorar el aprendizaje que posee, para enfrentar retos y mejorar día a día. Por ello, es relevante acercar los aprendizajes informales a los formales y articularlos, lo cual es una labor que el docente debe propiciar.

Se ha avanzado de una alfabetización digital a una más «informacional». Es importante diferenciar que no importa el estar conectado, si no se piensa ese escenario en función de una inteligencia colectiva, en un aprendizaje invisible para cada persona. La web social implica una suma de conocimientos y en las aulas se requiere favorecer el conocimiento colectivo, sumar necesidades de conocimiento y trabajar en los vacíos del conocer. Las experiencias educativas implican involucrar micro-transferencias de conocimiento, de conocimientos tácitos, de aprendizaje por observación y de aprendizaje por error.

En las aulas, los jóvenes tienen una presencia inerte, pasiva; lo que observan y escuchan no lo relacionan con su vida, con el contexto.

Hay que reinventar nuestra concepción del aprendizaje. Lo que tenemos ahora simplemente no funciona. Ha llegado la hora de aplicar un nuevo modelo (p. 189).

Un modelo educativo centrado en el «cómo» para «aprender a conocer»; un modelo centrado en el aprendizaje del estudiante.

Existe una preocupación acerca de la incapacidad de la escuela para adaptar los cambios sociales, tecnológicos y de la misma persona al siglo XXI. Con sus aprendizajes invisibles, la persona puede apoyar el 
conocimiento interrelacionando el contenido formal con sus experiencias de contextos y momentos. El aprendizaje — social y cotidiano- es una oportunidad para que los educadores repiensen sus procesos de enseñanza y reinventen su hacer docente.

Margarita Espinosa Jiménez 